\title{
Primary prevention of venous thromboembolism in elderly medical patients
}

\author{
Karine Lacut \\ Grégoire Le Gal \\ Dominique Mottier \\ GETBO EA 3878, CHU de Brest, \\ Department of Internal Medicine \\ and Chest Diseases, Hôpital Cavale \\ Blanche, Brest, France
}

\begin{abstract}
Primary prophylaxis with the use of an effective and safe intervention appears the best approach of venous thromboembolism (VTE) management in medical elderly patients, the most affected by VTE. With increasing life expectancy, prevention of VTE, particularly in elderly patients, will arise as a major public health problem. Few well designed clinical trials evaluating thromboprophylaxis in medical settings were conducted in the specific population of geriatric patients. However, among the several pharmacological treatments evaluated, low molecular weight heparins enoxaparin $40 \mathrm{mg}$ daily or dalteparin $5000 \mathrm{IU}$ daily appeared effective and safe in the prevention of VTE in elderly patients. Despite available data, and recommendations for VTE prevention in medical patients, thromboprophylaxis is underused or misused in practice. Heterogeneity of clinical studies, selected populations, concern about bleeding, and lack of a clear clinical benefit are some of the reasons that could explain the gap between theory and practice. In this review, after a brief report of epidemiologic data and specificities of VTE in elderly patients, the authors discuss the available results of VTE primary prevention trials for elderly medical patients, the limitations of these data, and the challenges to improve the practice and to reduce the incidence of this frequent but preventable disease.
\end{abstract}

Keywords: venous thromboembolism, prophylaxis, elderly patients, medical settings, review

\section{Introduction}

Venous thromboembolism (VTE) is a major cause of morbidity and mortality in hospitalized patients (Anderson et al 1991). Risk of VTE associated with surgical procedures is well established, and the benefit of thromboprophylaxis has been clearly demonstrated in surgical settings (Geerts et al 2004). Use of thromboprophylaxis is now a routine practice in patients undergoing surgery. However, recent epidemiological data suggested that the majority of VTE events acquired in hospitals occurred in medical, rather than in surgical patients (Lindblad et al 1991). Despite this, prevention of VTE in medical settings has been less extensively studied than in surgical settings. Nevertheless, some good-quality clinical trials have been conducted in the last decade in hospitalized medical patients, and guidelines now exist for these patients. Consensus guidelines published by the American College of Chest Physicians (ACCP) recommend prophylaxis with unfractionated heparin (UFH) or low molecular weight heparin (LMWH) in patients admitted to hospital with congestive heart failure or severe respiratory disease, or who are confined to bed and have one or more additional risk factors, including active cancer, previous VTE, sepsis, acute neurological disease, or inflammatory bowel disease (Geerts et al 2004).

Among medical patients, elderly patients deserve probably more attention than others as regards the risk and the prevention of VTE for many reasons. They are more affected by VTE than younger patients (Oger 2000); the proportion of severe and fatal VTE events is higher in those patients (Heit et al 2001); the association with other comorbidities is frequent (Kniffin et al 1994); diagnosis of 
pulmonary embolism (PE) is more difficult (Le Gal et al 2005; Righini et al 2005); and finally the risk of bleeding related to anticoagulant treatments is high (Lopez-Jimenez et al 2006), even more due to the high frequency of polymedication and interaction between used drugs. Therefore, prevention of VTE in this specific population is particularly challenging.

Despite relative high proportion of elderly patients included in the largest recent clinical trials of VTE prevention in medical settings (Samama et al 1999; Leizorovicz et al 2004; Cohen et al 2006), none were specifically conducted in the elderly population, and only a few other large, well designed, randomized controlled trials have been performed addressing this specific issue (Dahan et al 1986; Bergmann and Caulin 1996). Nevertheless some data from these studies are available for elderly patients and are discussed in this review. However, specific concerns, such as bleeding risk or lack of clinical benefit remain, and could explain why the systematic use of prophylaxis in elderly is not well implemented in medical wards (Anderson et al 2003).

After a report of VTE epidemiology and specificities in elderly medical patients, this review gives some practical advice, based on available data, to manage VTE prevention in older patients in medical wards. We also discuss the limits of current data and the challenges to improve the practice and reduce the incidence of VTE in elderly patients.

\section{Venous thromboembolism in elderly medical patients VTE: a disease of elderly patients}

The incidence of VTE increases with age. A populationbased study of patients discharged from hospital showed that the incidence of deep venous thrombosis (DVT) increased from 119 per 100,000 patients between 60-69 years old, to 291 per 100,000 patients $\geq 80$ years old (Anderson et al 1991). In France, the global annual incidence of symptomatic VTE was 1.83 per 1000 patients, but reached 10 per 1000 patients aged 75 years or older (Oger 2000). The increased incidence was noted for DVT, but also for PE. Moreover, because of the silent nature of the disease, the incidence of VTE was probably underestimated.

In a post-hoc analysis of MEDENOX study, age $>75$ years was found to be an independent risk factor of VTE (Alikhan et al 2004), and prevalence of VTE reached 18\% in patients $\geq 75$ years old from the placebo group (Alikhan et al 2003). Furthermore, elderly patients have often other acquired conditions recognized as risk factors for VTE that contribute to the high incidence of the disease (Kniffin et al 1994).

\section{High mortality rate in elderly patients}

The mortality of acute VTE in elderly is increased: $16 \%$ of patients over 80 years died early after the diagnosis of VTE, in comparison with $2 \%$ before 40 years, a difference that is confirmed and increased over 3.5 years of follow up (Anderson et al 1991). In the analysis of the RIETE registry, at three months after the venous thromboembolic event, $3.7 \%$ of patients aged $\geq 80$ years died of PE compared to $1.1 \%$ of patients $<80$ years (OR 3.6, 95\% CI 2.7-4.7) (Lopez-Jimenez et al 2006).

\section{More severe initial presentation in elderly patients}

In the study by Heit and colleagues (2001), there is a trend of a higher proportion of symptomatic $\mathrm{PE}$ in elderly: in patients over 70 years, PE is the manifestation of VTE in $70 \%$ of cases, in comparison with $55 \%$ of cases under 70 years. This finding is confirmed in the RIETE registry, where patients $\geq 80$ years old were more often enrolled with symptomatic PE (Lopez-Jimenez et al 2006). In this study, patients with VTE aged 80 or over more often weighed $<65 \mathrm{~kg}$, and had a higher rate of chronic lung disease, heart failure and creatinine clearance $<60 \mathrm{~mL} / \mathrm{min}$.

\section{Difficulties of diagnosis of PE in elderly patients}

Clinical symptoms and sign of PE are not specific, and PE can be a silent disease as well. Sometimes sudden death is the first clinical manifestation of PE. In autopsy studies, diagnosis of PE was suspected before death in only $10 \%$ of patients who died from proven PE (Sandler and Martin 1989). Diagnosis of PE is particularly difficult in elderly patients because the clinical presentation is less discriminative. The frequency of many cardiopulmonary underlying conditions that may mimic clinical presentation of PE is increased with age, and on the other hand, some classical signs of PE such as hemoptysis, tachycardia, hemidiaphragmatic elevation and pleural effusion were not associated with PE in patients aged 75 years or over (Le Gal et al 2005). The characteristics of diagnostic tests for PE are also unfavorably influenced by age (Righini et al 2005). In a study of 1029 consecutive patients presenting to the emergency department with clinically suspected PE, this diagnosis could be ruled out by a negative D-dimer test in $67 \%$ of patients 40 years or under, but in only $10 \%$ of patients aged 80 years 
or older (Righini et al 2000). Lung scan for PE diagnosis demonstrates a lower performance in elderly due to frequent underlying pulmonary diseases (Righini et al 2000), and finally, the frequency of renal impairment in elderly patients limits the use of CT-scan.

\section{High bleeding risk in elderly patients}

The main risk of treatment with anticoagulants, at therapeutic or prophylactic doses, is bleeding. Major data on the risk of bleeding is provided by trials on long term oral anticoagulation. These studies have shown that elderly patients with VTE have a higher risk of bleeding complications (Landefeld and Beyth 1993; White et al 1999; Levine et al 2001). In a prospective evaluation of an index for predicting the risk of major bleeding in outpatients treated with warfarin, age 65 years or greater was found to be an independent risk factor of major bleeding (Beyth et al 1998). In an analysis from the RIETE registry (Lopez-Jimenez et al 2006), 3.4\% of patients $\geq 80$ years old had major bleeding events compared to $2.1 \%$ of patients $<80$ years. Fatal bleeding occurred in $0.8 \%$ in the oldest and $0.4 \%$ among patients $<80$ years Recent bleeding, abnormal renal function (creatinine clearance $<60 \mathrm{~mL} / \mathrm{min}$ ), use of corticosteroids or long term therapy with LMWH were independently associated with an increased risk of major bleeding. Other results from the same registry have also shown that major and fatal bleeding events occurred more frequently in acutely ill medical patients than in surgical patients (Monreal et al 2004).

In the case of severe renal insufficiency, UFH can be used, while LMWH are usually contraindicated. However, UFH was also associated with a higher risk of bleeding in the elderly (Campbell et al 1996).

During VTE prophylaxis, results from a meta-analysis of clinical trials conducted in medical settings showed that the incidence of major bleeding was $0.4 \%$ in heparin groups, compared to $0.2 \%$ in control groups (Mismetti et al 2000). In the recent trials, this incidence varied from $0.2 \%$ to $1.7 \%$ in the treatment groups (Samama et al 1999; Leizorovicz et al 2004; Cohen et al 2006).

\section{VTE: a complication of medical illness}

VTE is a major cause of morbidity and mortality in hospitalized patients (Anderson et al 1991). It has been reported that $10 \%$ of deaths occurring during hospitalization were related to PE (Sandler and Martin 1989). Autopsy studies revealed that $70 \%$ to $80 \%$ of all in-hospital deaths related to PE were not associated with surgical procedures, but occurred in medical patients (Goldhaber et al 1983;
Sandler and Martin 1989; Lindblad et al 1991; Baglin et al 1997). Hospitalization for an acute medical illness was also recognized as an independent factor of VTE associated with about an 8-fold increased relative risk for VTE (Heit et al 2000). Moreover, the initial presentation and outcomes of VTE were more severe and frequent in patients who developed VTE after an acute medical illness than in patients who developed VTE after a surgical intervention (Monreal et al 2004).

Before the publication of the more recent large clinical trials, the incidences of DVT (including asymptomatic DVT) and clinical $\mathrm{PE}$ in medical patients not receiving prophylaxis were respectively estimated at about 19\% and 1\% (Mismetti et al 2000). Results from recent large clinical trials for VTE incidence rates in placebo groups were: $15 \%$ in the MEDENOX study (Samama et al 1999), 5\% in PREVENT study (Leizorovicz et al 2004), and 11\% in ARTEMIS study (Cohen et al 2006). Differences in asymptomatic outcomes definition (proximal alone or distal and proximal DVT), and methods to measure these outcomes (venography or compression ultrasonography) could explain this relatively wide interval for incidence rates.

Among hospitalized patients, elderly medical patients are probably the most affected by VTE. As a result, the proportion of preventable events by an effective thromboprophylaxis is expected to be high in this population. Moreover, because of VTE specificities in elderly (high mortality rate, severe initial presentation, difficult diagnosis of $\mathrm{PE}$ and high risk of major bleeding with anticoagulant drugs at therapeutic doses), primary prophylaxis with the use of an effective and safe intervention appears to be the best approach to VTE management.

\section{Management of thromboprophylaxis in elderly medical patients Do all hospitalized elderly medical patients need a thromboprophylaxis?}

The first question in front of a newly admitted elderly patient is whether they will require prevention against VTE; in other words, we have to systematically assess the individual risk of venous thrombosis, and select the patients for whom thromboprohylaxis would be helpful.

This assessment, and therefore the decision of prescribing a prophylaxis, should be based on the presence or absence of specific risk factors (Table 1). Previous studies have identified a number of risk factors for VTE in medical patients (Anderson et al 1991; Samama 2000; Heit et al 2001; 
Table I Risk factors of venous thromboembolism in medical patients

\begin{tabular}{lll}
\hline Permanent underlying risk conditions & Acute medical conditions & latrogenic risk factors \\
\hline Advanced age ( $>75$ years $)$ & Heart failure & Hormone replacement therapy \\
History of VTE & Severe respiratory diseases & Hospital or nursing home confinement \\
Varicose veins & Acute infectious diseases & \\
Obesity & Malignancy & Chemotherapy \\
Malignancy & Stroke & Central venous catheter \\
Thrombophilia & Prolonged immobilization $(>3$ years $)$ & \\
& Myocardial infarction & \\
\hline
\end{tabular}

Heit et al 2002; Arcelus et al 2003). Many of these factors are frequent in elderly hospitalized patients, alone or combined and generally cumulative (Kniffin et al 1994; Rosendaal 1999). However, individual risk assessment in medical settings can be problematic in practice.

In clinical trials on thromboprophylaxis in medical settings, eligibility criteria included most of the various risk factors (Table 2) but they differ between studies and cannot be easily repeated (Samama et al 1999; Leizorovicz et al 2004; Cohen et al 2006). Thromboprophylaxis has been studied specifically in some medical conditions such as stroke (Kamphuisen and Agnelli 2007; Sherman et al 2007), myocardial infarction (Pitt et al 1980) or cancer (Levine et al 1994; Kakkar et al 2004). Instead of providing clarification, the decision of whom and how to treat may become more difficult as a result.
Nevertheless, assessment of the risk of VTE is probably easier for elderly than for other medical patients. Because age over 75 years is an independent risk factor of VTE in medically ill patients (Alikhan et al 2004), the presence of only one additional acute medical condition is required to consider thromboprophylaxis for these patients, using for example the risk assessment model developed by Cohen and colleagues (2005). A thromboprophylaxis should be proposed if the hospitalization is motivated by one of these following conditions: acute myocardial infarction, acute heart failure, active cancer requiring therapy, acute infectious disease, respiratory disease, acute rheumatologic disease, ischemic stroke, paraplegia, and inflammatory disorder with immobility or inflammatory bowel disease.

Table 2 Eligibility criteria in MEDENOX, PREVENT, and ARTEMIS clinical trials

\begin{tabular}{|c|c|c|}
\hline MEDENOX & PREVENT & ARTEMIS \\
\hline Age $\geq 40$ years & Age $\geq 40$ years & Age $\geq 60$ years \\
\hline - Expected hospital stay $\geq 6$ days & - Expected hospital stay $\geq 4$ days & - Expected bed rest $\geq 4$ days \\
\hline - Recent immobilization ( $\leq 3$ days) & - Recent immobilization ( $\leq 3$ days) & - Congestive heart failure (NYHA \\
\hline $\begin{array}{l}\text { - Congestive heart failure (NYHA III/IV) or acute } \\
\text { respiratory failure, or one medical condition if } \\
\text { associated with at least one additional risk factor } \\
\text { of VTE. }\end{array}$ & $\begin{array}{l}\text { - Congestive heart failure (NYHA III/IV) or acute } \\
\text { respiratory failure or one medical condition if } \\
\text { associated with at least one additional risk } \\
\text { factor of VTE. }\end{array}$ & $\begin{array}{l}\text { III/IV) or acute respiratory illness in } \\
\text { the presence of chronic lung disease, } \\
\text { or clinically diagnosed acute infections } \\
\text { or inflammatory disorders such as } \\
\text { arthritis, connective tissue diseases, or } \\
\text { inflammatory bowel disease. }\end{array}$ \\
\hline
\end{tabular}

Medical conditions were: acute infection without septic shock; acute rheumatic disorders, including acute lumbar pain or sciatica or vertebral compression (caused by osteoporosis or a tumor), acute arthritis of the legs, or an acute episode of rheumatoid arthritis in the legs, or an episode of inflammatory bowel disease.

Additional risk factors of VTE were: age $\geq 75$ years, cancer, previous VTE, obesity, varicose veins, hormone therapy (antiandrogen or estrogen, except for postmenopausal hormone-replacement therapy), and chronic heart or respiratory failure
Medical conditions were: infection without septic shock, acute rheumatologic disorders, or inflammatory bowel disease
Additional risk factors of VTE were: age $\geq 75$ years, cancer, previous VTE, obesity, varicose veins and/or chronic venous insufficiency, hormone replacement therapy, history of chronic heart failure, chronic respiratory failure, or myeloproliferative syndrome. 
In conclusion, elderly medical patients should receive a thromboprophylaxis if an acute medical illness is the leading cause of hospitalization.

\section{Which prophylaxis should be used?}

Among thromboprophylactic methods, anticoagulant treatments with UFH or LMWH are the regimens of choice, but they share main contraindications: untreated hemophilia and other hemorrhagic disorder, active bleeding or perceived bleeding risk ( peptic ulcer, recent cerebral hemorrhage, severe hypertension, and severe liver disease), thrombocytopenia with platelets $<60 \times 10^{9} / \mathrm{L}$, a history of heparin-induced thrombocytopenia, and hypersensitivity to heparin.

Because of its principally renal route of elimination, LMWH, even at prophylactic doses, must be used with caution in patients with renal failure. When creatinine clearance is less than $30 \mathrm{~mL} / \mathrm{min}$, UFH may be preferred.

Before prescribing an anticoagulant regimen, we need to check systematically the potential contraindications: baseline risk of bleeding, platelets count and renal function. In the event that there is a contraindication to pharmacological thromboprophylaxis, consider nonpharmacological treatments. Nonpharmacological strategies include graduated compression stockings, intermittent pneumatic compression, leg elevation, and early mobilization. No randomized clinical trials have evaluated mechanical methods of prophylaxis in general medical patients. These measures should be considered as alternative methods when contraindications to anticoagulants exist (Geerts et al 2004).If there is no contraindication to pharmacological treatments, use LMWH or UFH.

\section{Prophylactic treatment versus placebo (Table 3)}

Seven trials comparing a prophylactic heparin treatment to a control $(15,095$ patients) in medical patients were selected in the meta-analysis by Mismetti and colleagues (2000). Four studies evaluated UFH at 10000 IU or 15000 IU daily (Belch et al 1981; Cade et al 1982; Ibarra-Perez et al 1988; Gardlund 1996) and three studies evaluated a LMWH (enoxaparin or nadroparin) (Dahan et al 1986; Bergmann and Caulin 1996; Fraisse et al 2000). A significant decrease in DVT and in clinical PE were observed with heparins as compared to control (risk reductions of $56 \%$ and $58 \%$ respectively, $\mathrm{p}<0.001$ in both cases), without significant difference in the incidence of major bleedings or deaths.

In the MEDENOX study, patients of 75 years or older accounted for more than half of acute ill medical patients included in the trial (Samama et al 1999). A post-hoc analysis was performed in the subgroup of older patients (Alikhan et al 2003). Those who received $40 \mathrm{mg}$ enoxaparin had a $78 \%$ reduction in VTE when compared with placebo (absolute risk reduction 14.4\%; relative risk [RR] $0.22 ; 95 \%$ CI, $0.09-0.51)$. The incidence of adverse effects, including hemorrhages, did not differ significantly between the placebo group and either enoxaparin group in the primary analysis, but no data were reported for the subgroup of elderly patients.

The PREVENT trial included medical patients randomized to receive dalteparin, 5000 IU once daily, or placebo (Leizorovicz et al 2004). In the subgroup of patients 75 years or older, who represented one third of the population included in the trial, the primary end point was reported in $4.2 \%$ with dalteparin and $8.0 \%$ with placebo (RR $0.52 ; 95 \%$ CI, 0.31-0.87) (Kucher et al 2005b). Dalteparin was not associated with a significant increase in major hemorrhage ( $1.1 \%$ vs $0.7 \%$; $=0.12$ ).

The ARTEMIS study was designed to evaluate the efficacy and safety of the anticoagulant fondaparinux in older acute medical inpatients at moderate to high risk of VTE (Cohen et al 2006). To our knowledge, no specific data concerning the subgroup of elderly patients were already published.

Two double-blind randomized studies evaluated thromboprophylaxis without systematic assessment of asymptomatic DVT at the end of the treatment period (Bergmann and Caulin 1996; Lederle et al 2006). In the first study, nadroparin did not have a significant effect on mortality and the study provided no data suggesting that nadroparin may reduce the incidence of thromboembolic events in patients hospitalized for an acute medical disease (Bergmann and Caulin 1996; Mahe et al 2005). In the second study, the primary outcome was the total mortality at 90 days after randomization, but authors reported also the number of readmission due to objectively proven symptomatic venous thromboembolic events occurring within 90 days of randomization (Lederle et al 2006). Overall mortality and occurrence of clinical thromboembolic events did not differ between enoxaparin and placebo.

\section{Comparison of prophylactic anticoagulant regimens}

A meta-analysis of eight trials comparing UFH and LMWHs in medical patients found no significant differences between the two treatment groups on the incidence of DVT, clinical PE or mortality (Mismetti et al 2000). However, LMWH 
Table 3 Double-blind randomized clinical trials evaluating thromboprophylaxis versus placebo in various medical patients

\begin{tabular}{|c|c|c|c|c|c|c|}
\hline $\begin{array}{l}\text { Author, study, } \\
\text { year }\end{array}$ & Treatment & $\begin{array}{l}\text { Treatment } \\
\text { duration }\end{array}$ & $\begin{array}{l}\text { Eligible age } \\
\text { (mean age) } \\
\text { in years }\end{array}$ & $\begin{array}{l}\text { Number of } \\
\text { patients }\end{array}$ & Primary outcome & $\begin{array}{l}\text { Results: Efficacy of } \\
\text { thromboprophylaxis } \\
\text { vs placebo }\end{array}$ \\
\hline Dahan et al 1986 & $\begin{array}{l}\text { Enoxaparin } 60 \mathrm{mg} \\
\mathrm{sc} \text { od }\end{array}$ & $\begin{array}{l}\text { Until discharge } \\
\text { or } 10 \text { days }\end{array}$ & $\geq 65(80)$ & 270 & $\begin{array}{l}\text { DVT diagnosed by }{ }^{125} \\
\text { fibrinogen scanning }\end{array}$ & $\begin{array}{l}\text { DVT: } 3 \% \text { in enoxaparin } \\
\text { group vs } 9.1 \% \\
\text { in placebo group } \\
(p=0.03)\end{array}$ \\
\hline $\begin{array}{l}\text { Bergmann and } \\
\text { Caulin I } 996 \\
\text { (Mahe et al 2005) }\end{array}$ & $\begin{array}{l}\text { Nadroparin } \\
0.3 \mathrm{~mL} \text { sc od }\end{array}$ & $\begin{array}{l}\text { For up to } \\
21 \text { days }\end{array}$ & $\geq 40(76)$ & 2474 & $\begin{array}{l}\text { Total mortality at the end } \\
\text { of the study time, defined } \\
\text { as } 21 \text { days or death. }\end{array}$ & $\begin{array}{l}\text { Mortality: } 10.1 \% \text { in } \\
\text { nadroparin group } \\
\text { vs } 10.3 \% \text { in placebo } \\
\text { group (NS) }\end{array}$ \\
\hline $\begin{array}{l}\text { Samama et al } \\
\text { MEDENOX } 1999\end{array}$ & $\begin{array}{l}\text { Enoxaparin } 40 \text { mg } \\
\text { sc od Enoxaparin } \\
20 \mathrm{mg} \mathrm{sc} \text { od }\end{array}$ & $\begin{array}{l}\text { For } 14 \text { days } \\
\text { (mean duration: } 7 \\
\text { days) Follow-up } \\
110 \text { days }\end{array}$ & $\geq 40$ (73) & 1102 & $\begin{array}{l}\text { VTE defined as asymp- } \\
\text { tomatic DVT detected } \\
\text { by bilateral venography } \\
\text { or ultrasonography or } \\
\text { symptomatic DVT or } \\
\text { documented PE }\end{array}$ & $\begin{array}{l}\text { VTE: I5.0\% in } \\
\text { enoxaparin } 20 \mathrm{mg} \\
\text { group vs I4.9\% in } \\
\text { placebo group (NS) } \\
\text { VTE: } 5.5 \% \text { in enoxa- } \\
\text { parin } 40 \mathrm{mg} \text { group vs } \\
\text { I } 4.9 \% \text { in placebo group } \\
(\mathrm{P}<0.00 \mathrm{I})\end{array}$ \\
\hline $\begin{array}{l}\text { Leizorovicz et al } \\
\text { PREVENT } 2004\end{array}$ & $\begin{array}{l}\text { Dalteparin } 5000 \\
\text { IU sc od }\end{array}$ & $\begin{array}{l}\text { For } 14 \text { days } \\
\text { Follow-up } \\
90 \text { days }\end{array}$ & $\geq 40$ (68.5) & 3706 & $\begin{array}{l}\text { VTE defined as symptom- } \\
\text { atic DVT (proximal or } \\
\text { distal), fatal or symptom- } \\
\text { atic nonfatal PE, sudden } \\
\text { death, and asymptomatic } \\
\text { proximal DVT detected } \\
\text { by ultrasonography at } \\
\text { day } 21\end{array}$ & $\begin{array}{l}\text { VTE: } 2.8 \% \text { in dalte- } \\
\text { parin group vs } 5.0 \% \\
\text { in placebo group } \\
(p=0.0015)\end{array}$ \\
\hline $\begin{array}{l}\text { Cohen et al } \\
\text { ARTEMIS } 2006\end{array}$ & $\begin{array}{l}\text { Fondaparinux } \\
2.5 \mathrm{mg} \mathrm{sc} \text { od }\end{array}$ & $\begin{array}{l}\text { For } 14 \text { days } \\
\text { (median of } 7 \text { days) } \\
\text { Follow-up } 32 \text { days }\end{array}$ & $\geq 60(75)$ & 849 & $\begin{array}{l}\text { VTE defined as } \\
\text { symptomatic DVT or PE } \\
\text { or asymptomatic DVT } \\
\text { detected by bilateral } \\
\text { venography }\end{array}$ & $\begin{array}{l}\text { VTE: } 5.6 \% \text { in } \\
\text { fondaparinux group vs } \\
10.5 \% \text { in placebo group } \\
(p=0.029)\end{array}$ \\
\hline Lederle 2006 & $\begin{array}{l}\text { Enoxaparin } \\
40 \mathrm{mg} \mathrm{sc} \text { od }\end{array}$ & $\begin{array}{l}\text { Until discharge } \\
\text { Follow-up } 90 \text { days }\end{array}$ & $\geq 60(71.5)$ & 280 & Total mortality at 90 days & $\begin{array}{l}\text { Mortality: } 9.3 \% \text { in } \\
\text { enoxaparin group } \\
\text { vs } 10 \% \text { in placebo } \\
\text { group (NS) }\end{array}$ \\
\hline
\end{tabular}

seemed to be safer than UFH by reducing the risk of major hemorrhage (RR 52\%, p = 0.049).

In the recent meta-analysis by Wein et al (2007) that included studies of patients with acute ischemic stroke, LMWH was associated with a reduced risk of DVT (RR, $0.68 ; 95 \%$ CI, 0.52-0.88) and injection site hematoma (RR, 0.47; 95\% CI, 0.36-0.62) compared with UFH. No statistically significant differences were observed between the two treatments with respect to PE, mortality, total bleeding, and major or minor bleeding.

Enoxaparin $20 \mathrm{mg}$ once daily and UFH 5000 IU twice daily were considered equivalent in terms of efficacy in patients aged 65 years or more (mean age 83 years) and no significant difference was found in terms of safety (Bergman and Neuhart 1996). However, MEDENOX study suggested that enoxaparin at $20 \mathrm{mg}$ was ineffective for preventing VTE in acutely ill medical patients compared to placebo (Samama et al 1999).

Enoxaparin $40 \mathrm{mg}$ subcutaneously once daily was shown to be as effective as UFH 5000 IU three times daily in the PRIME and PRINCE studies (Lechler et al 1996; Kleber et al 1998). The PRIME study included various medical patients (mean age 74 years), and the PRINCE study included patients (mean age 70 years) with severe respiratory disease or heart failure.

The recent PREVAIL study was designed to assess the efficacy and safety of enoxaparin versus UFH for the prevention of VTE in patients with acute ischemic stroke (Sherman et al 2007). The mean age of included patients was 66 years, and $25 \%$ of patients were older than 75 years. More than 
$90 \%$ of patients received a concomitant medication by an antiplatelet drug. Enoxaparin was significantly more effective than UFH for the prevention of VTE in patients with acute ischemic stroke (RR 0.57, 95\% CI 0.44-0.76), without significant difference in terms of bleedings ( $8 \%$ vs $8 \% ; \mathrm{p}=0.83)$ or symptomatic intracranial hemorrhage $(1 \%$ vs $1 \% ; \mathrm{p}=0.55)$.

No studies have directly compared different modalities of UFH administration. However, a recent meta-analysis comparing UFH given twice daily or 3 times daily from 12 studies found no difference in the overall rate (per 1000 patient-days) of VTE (twice daily: 5.4 vs 3 times daily: 3.5; $\mathrm{p}=0.87$ ), but an increased risk of major bleedings with three times daily heparin (twice daily: 0.35 vs 3 times daily: 0.96 ; $\mathrm{p}<0.001$ ) (King et al 2007).

In regards to the risk of heparin-induced thrombocytopenia (HIT) that should be considered when providing patients with thromboprophylaxis, LWMHs appeared safer than UFH in surgical patients (Warkentin et al 1995). However, in the recent meta-analysis by Wein and colleagues (2007), no statistically significant differences were observed between UFH and LMWH with respect to thrombocytopenia (RR, 0.25; 95\% CI, 0.05-1.16).

\section{Cost effectiveness analyses}

Several studies conducted in different countries have evaluated the cost effectiveness of LMWH relative to UFH or to no pharmacological prophylaxis for DVT prevention in medical inpatients (Lamy et al 2002; Nuijten et al 2002; McCarry et al 2004; Schadlich et al 2006; Shorr et al 2007). Regardless of some methodological differences, they conclude that, despite higher acquisition costs, LMWHs for thromboprophylaxis in medical patients resulted in savings compared to no pharmacological prophylaxis and were associated with lower costs or at least neutral cost compared with UFH.

To conclude, based on the results of the clinical trials presented above, elderly patients hospitalized for an acute medical illness should receive a prophylactic anticoagulant treatment unless there is a contraindication. LMWHs, enoxaparin at the dose of $40 \mathrm{mg}$ and dalteparin at the dose of $5000 \mathrm{IU}$, are effective and safe to prevent VTE in elderly patients. Compared to UFH, they are more convenient, requiring only one subcutaneous injection daily. They are associated with a lower risk of heparin-induced thrombocytopenia, and finally are equal or superior in cost effectiveness analyses. In case of severe alteration of renal function however, the safety of LMWHs is uncertain and UFH should be considered. More data are needed to recommend the use of fondaparinux as a routine treatment in elderly patients. In case of contraindication to heparins, graduated stockings or intermittent pneumatic compression should be used.

\section{For how long should the treatment be given?}

In the main randomized trials, prophylactic treatment was given for 1 to 2 weeks. While no specific recommendations exist regarding the duration of anticoagulant treatment, treatment would therefore not exceed this length. However, some elements could be discussed in favor of duration extension in medical patients, and especially in elderly medical patients.

First, it is likely that the thrombotic process has already started in some patients before their admission to hospital. In a study evaluating the prevalence of VTE in medical patients hospitalized for another reason than VTE, asymptomatic VTE at admission was diagnosed in $17.8 \%$ of patients over 80 years (Oger et al 2002).

Second, in the MEDENOX, PREVENT and ARTEMIS studies, additional symptomatic VTE events and fatal PE occurred after discontinuation of prophylaxis during the follow up period in the treatment groups (Samama et al 1999; Leizorovicz et al 2004; Cohen et al 2006).

Third, extension of prophylaxis duration was shown to be effective in other settings. In major orthopedic surgery, a meta-analysis of randomized trials confirmed that prolonged prophylaxis with LWMH for one month postoperatively, compared with the standard practice of prescribing prophylaxis for 7-10 days, reduced the relative risk of all DVT events by $59 \%(\mathrm{p}<0.001)$, and reduced the risk of symptomatic VTE by $64 \%$ ( $p<0.001$ ), without increasing bleeding complications (Hull et al 2001). Benefit of prolonged prophylaxis to 25-31 days was also demonstrated in patients with active cancer who were undergoing surgery (Berqvist et al 2002).

The Extended Clinical Prophylaxis in Acutely III Medical Patients (EXCLAIM) trial was designed to demonstrate the superiority of extended-duration prophylaxis with enoxaparin (28 \pm 4 days) compared with the standard regimen of enoxaparin (10 \pm 4 days) for prevention of VTE in acutely ill medical patients with recent reduced mobility (Hull et al 2007). Mean age of included patients was 70 years, with more than $40 \%$ of patients being 75 years or older. Extendedduration prophylaxis with enoxaparin was more effective than standard regimen of enoxaparin on the primary efficacy endpoint (asymptomatic DVT detected by ultrasonography, symptomatic DVT, symptomatic PE, fatal PE) (2.8\% vs $4.9 \%$, RR 0.56, 95\% CI 0.39-0.80). However, major hemorrhagic 
complications occurred significantly more frequently with the extended-duration prophylaxis $(0.60 \%$ vs $0.15 \%$, RR 4.03 ; 95\% CI 1.14-14.3) (Hull et al 2007).

One or two weeks is the common duration of prophylactic treatment with LMWH or UFH. Extension of prophylaxis duration to one month appeared to be more effective than standard duration but was also associated with an excess of major bleedings. Awaiting further analyses of the EXCLAIM study, extended-duration prophylaxis in medical patients should be discussed on a case-by-case basis.

\section{Is a monitoring of pharmacological prophylaxis required?}

The highest risk of anticoagulant prophylaxis is bleeding. Even if major bleedings are less frequent with prophylactic than with therapeutic doses, physicians should be aware of this risk, and should observe their patients regularly by clinical examination for all potential bleedings. Moreover, underlying conditions or associated treatments could change during hospitalization, and this could increase the bleeding risk associated with thromboprophylaxis. A regular reassessment of the benefit and risk of thromboprophylaxis decided on admission should be performed taking into account the potential modifications since admission, for example, the modifications of renal function or the presence of a newly diagnosed contraindication. However, no specific biological monitoring is needed to evaluate the anticoagulant activity of UFH or LMWH at prophylactic doses.

Less frequent, but often fatal, is the potential development of HIT. Even if HIT appeared to be less frequently observed with LMWH than with UFH, a monitoring of platelets count is required at least twice weekly for all heparins during the treatment period (Warkentin and Greinacher 2004).

Regular assessment of bleeding risk associated with thromboprophylaxis should be performed, taking into account the potential changes in underlying conditions and associated treatments. A monitoring of platelets count is required for UFH as well as for LMWH.

A proposition of management of thromboprophylaxis in elderly medical patients is resumed in Figure 1.

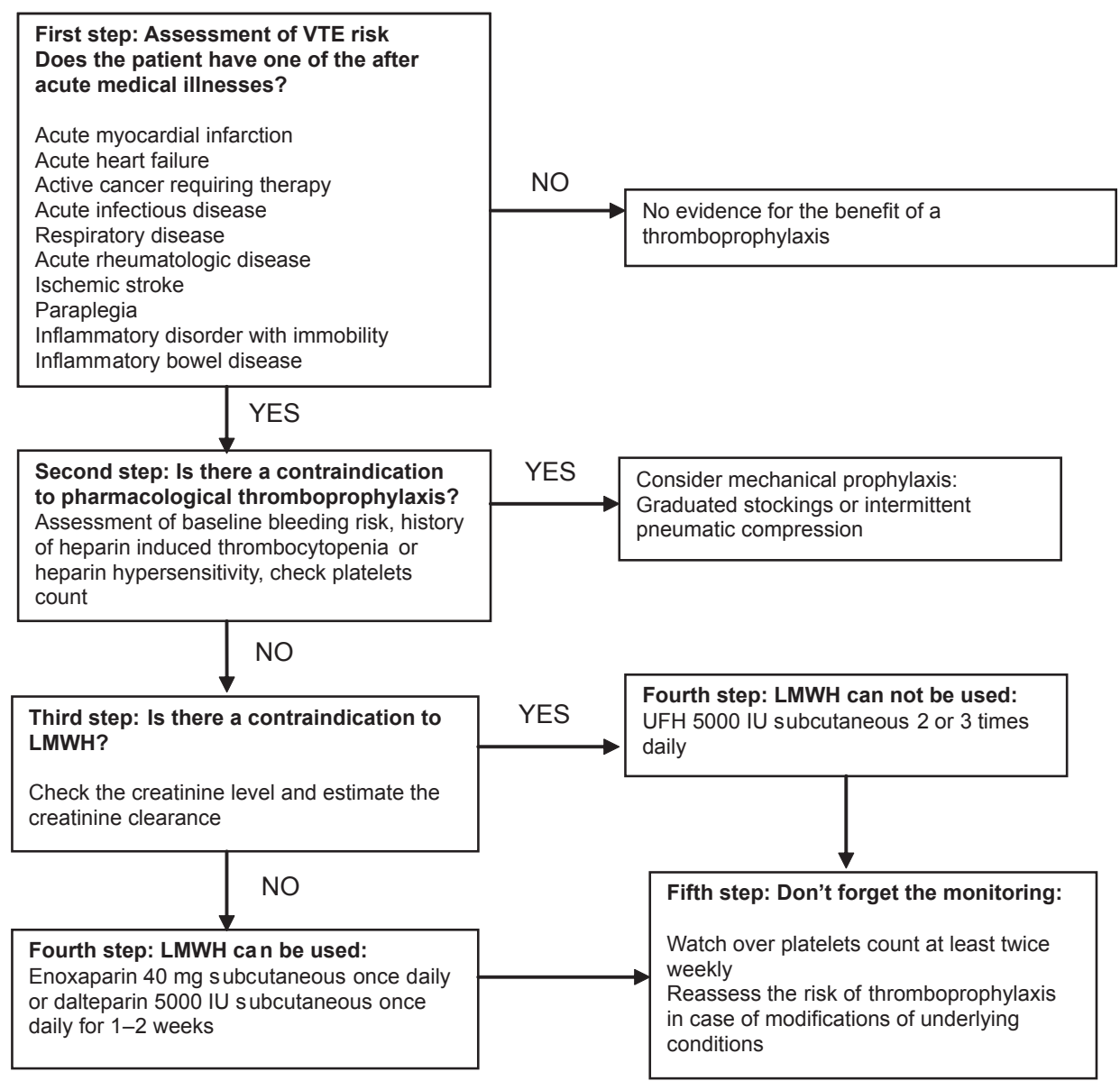

Figure I Management of thromboprophylaxis in elderly ( $>75$ years) medical patients. 


\section{Why is thromboprophylaxis in the elderly not better adopted in clinical practice? \\ The gap between theory and practice}

Despite available data, and recommendations for VTE prevention in medical patients, underuse or misuse of thromboprophylaxis remains a problem. A case series study showed that among 208 patients who developed acute VTE during hospitalization in medical wards, only $48 \%$ had received VTE prophylaxis (Goldhaber et al 2000). Recently, the Canadian CURVE study aimed to determine the proportion of hospitalized, acutely ill medical patients who were eligible to receive thromboprophylaxis, and to evaluate the frequency, determinants and appropriateness of its use (Kahn et al 2007). Following ACCP guidelines, authors found that of the 1894 medical hospitalized patients who were eligible for study inclusion, 90\% should receive a thromboprophylaxis. However, only $23 \%$ received a prophylaxis, and only $16 \%$ received an appropriate thromboprophylaxis.

Use of prophylaxis in elderly medical patients is unknown, but thought to be as low as in general medical patients. Nevertheless, in CURVE study, age was not found as a determinant of thromboprophylaxis use (Kahn et al 2007), and in IMPROVE study, prophylaxis with LMWH or UFH was more likely to be used if patients were aged $\geq 85$ years (Tapson et al 2007). In the study by Chopard and colleagues (2005), patients treated by thromboprophylaxis were older than those without prophylaxis. The rate of patients needing thromboprophylaxis and not receiving it was lower for older patients ( $>75$ years) than for younger patients. However, the rate of patients not needing thromboprophylaxis and receiving it was higher for older patients than for younger patients.

\section{Explaining the gap}

The gap between theory and practice for the use of thromboprophylaxis could be explained by many reasons. Heterogeneity of clinical studies, selected populations, concern about bleedings, and the lack of a clear clinical benefit are some of these reasons.

\section{Heterogeneity of clinical trials}

Clinical trials highlighted the benefit of pharmacological treatment for VTE prevention in medical patients (Samama et al 1999; Leizorovicz et al 2004; Cohen et al 2006). However, the different rates of VTE incidence from $4.8 \%$ to $14.9 \%$ in the placebo groups suggested disparities between studies. This may reflect the heterogeneous medical conditions of the different populations studied, as well as differences in the endpoints and outcomes measure. In fact, any study could be directly compared to another. When two studies shared the same inclusion criteria, treatments and/or primary end points and/or modalities to measure the outcomes were different.

As presented in Table 2, eligibility criteria of clinical trials, and the resulting validated indications of thromboprophylaxis evaluated in these trials are various and different between studies. Compared to surgical settings, there is a lack of legibility of eligibility criteria for the use of thromboprophylaxis in medical settings. This complexity is discouraging and could explain its underuse.

Homogenization of outcomes definition, outcomes measure and simplification of eligibility criteria are probably needed for further trials. This may help to clarify the recommendations and to improve the practice.

\section{Selected medical populations, and probably high selected elderly populations}

Inclusion and exclusion criteria of clinical trials lead to selected populations, and results should be interpreted with caution before being extrapolated to a larger population. Taking into account the high proportion of patients hospitalized in medical wards, the number of patients included in the clinical trials was low. In IMPROVE, only $13 \%-19 \%$ of all patients would have been eligible for inclusion in MEDENOX, PREVENT, or ARTEMIS studies (Anderson et al 2003). This problem can be also illustrated by the results of the CURVE study (Kahn et al 2007). Over the 3-week study period, in 29 hospitals across Canada, 1702 medical patients had an indication of thromboprophylaxis. This number is higher than the number of included patients in MEDENOX study over 18 months in 60 centers from nine countries.

Furthermore, many patients who were usually hospitalized in geriatric units, were unable to sign a written informed consent, presented alteration of renal function or low weight were excluded from these trials. Renal insufficiency and low weight, two frequent conditions in elderly patients and associated with higher risk of bleeding (Lopez-Jimenez et al 2006), were often exclusion criteria. Therefore, selection of a population with low risk of bleeding in clinical trials was likely and concern about bleeding with thromboprophylaxis could be a reason of its underuse in elderly patients. Moreover, as an informed consent is required, patients need to understand and approve the enrolment in the study. Unfortunately, only few patients among the oldest are able to give such consent, 
because of impairment of cognitive functions, or too severe weakness to be able to participate.

Despite findings of clinical trials suggesting that thromboprophylaxis is effective and safe in the elderly patients, few trials enrolled specifically geriatric patients. Additionally, elderly patients were probably highly selected and therefore not representative of overall elderly medical patients.

\section{Lack of evident clinical benefit?}

Only few trials were conducted using symptomatic VTE and/or mortality as the primary end point. In the majority of clinical trials, the primary end point was a combined outcome including symptomatic VTE (DVT and/or fatal and non fatal PE) and asymptomatic DVT systematically assessed at the end of the treatment period. Asymptomatic DVT, however, were the great majority of events detected during the studies. In medical patients, there is a lack of evidence that prophylaxis prevents clinically important outcomes, such as PE, which has been shown in surgical patients (Collins et al 1988). Therefore, some could argue about the clinical relevance of the results from trials conducted in medical settings.

A recent meta-analysis aimed to evaluate the effects of anticoagulant prophylaxis in reducing clinically important VTE outcomes in hospitalized medical patients (Dentali et al 2007). Prophylaxis (with UFH, LMWH or fondaparinux) was associated with a significant reduction of any PE (RR: 0.43, CI, 0.26-0.71) and fatal PE (RR: 0.38, CI, 0.21-0.69), a nonsignificant reduction in symptomatic DVT and a nonsignificant increase in major bleeding. Anticoagulant prophylaxis had no effect on all-cause mortality. However, the main limitation of this analysis is that the results concerned only the treatment period. How are they maintained after the treatment has been stopped (which is really the relevant question) is unknown.

The benefit of prophylaxis in medical patients is uncertain for clinical nonfatal VTE events, and no benefit on overall mortality was demonstrated. How these results are relevant for elderly population remains to be determined.

\section{Challenges to improve the practice}

As life expectancy is increasing in developed countries, incidence of VTE is also expected to increase. How to prevent this potential fatal disease will arise as a major public health problem for the next decades. According to the Agency for Healthcare Research and Quality in the United States, prevention of VTE in adult patients in hospital was the main challenge to patient safety in 2001 (Agency for Healthcare Research and Quality 2001).
Therefore, many efforts have to be done to improve thromboprophylaxis particularly in the elderly. Determining the optimal strategy of prevention is essential and further trials conducted specifically in the elderly nonselected patients and evaluating the benefit-risk ratio of thromboprophylaxis are needed. However, available results suggested that some prophylactic treatments were effective and safe even in the older patients. These treatments should be more used in practice following the available guidelines. But the use of such treatments in the "real life" and for patients that would have not been included in the clinical trials must be evaluated. Reducing the gap between theory and practice shown by many studies should reduce the number of patients exposed to high risk of thrombosis and not receiving effective prevention.

To improve practice, some suggestions should be proposed in all hospitals:

- Results of epidemiologic studies highlighted the importance of VTE in in-hospital morbi-mortality should be largely taught. This would reduce the lack of awareness that VTE is a real public health problem among all practitioners.

- Models of assessment of the VTE risk should be validated and more used. Assessment of the risk of VTE for all medical patients is the first recommendation of current guidelines (Nicolaides et al 2001; Geerts et al 2004). However, assessing the individual risk of VTE in medical settings is difficult. Models to assess this risk have been developed to assist the physicians to determine if thromboprophylaxis is warranted or not (Samama et al 2003, 2006; Cohen et al 2005). But these models have not been validated in specifically designed prospective clinical trials, they are less structured than in surgical settings and are not conceived for elderly patients. Nevertheless, systematic assessment of VTE risk at admission has been shown to improve the prophylaxis practice in an original initiative conducted in Brigham and Women's Hospital in Boston (Kucher et al 2005a). A computer program linked to the patient database was developed to identify consecutive hospitalized patients at risk for DVT in the absence of prophylaxis. Eligible patients were randomly assigned to an intervention group, in which the responsible physician was alerted to a patient's risk of DVT, and to a control group, in which no alert was issued. The computer alert reduced the risk of VTE at 90 days by $41 \%$ (HR, 0.59; 95\% CI, $0.43-0.81)$. These encouraging findings suggested that alerting physicians to the individual risk of VTE could contribute to improve the rate of clinical outcomes. 
- Regular updates on prevention of VTE in medical settings should also be proposed in Continuing Medical Education programs. On these occasions, last data and last recommendations of experts could be presented and discussed.

Finally, further studies are needed to determine the place of the new anticoagulant drugs, such as direct Factor $\mathrm{Xa}$ inhibitors or antithrombin inhibitors, in the prevention of VTE in medical settings. Besides their effectiveness and safety demonstrated in surgical settings, their pharmacokinetic properties (that allow one oral daily dose) provide other advantages that should be useful in daily practice.

\section{Conclusions}

Elderly patients are the most concerned by VTE, and development of optimal thromboprophylaxis strategies should be a priority in this population. Further clinical trials evaluating efficacy and risk of thromboprophylactic methods, including new anticoagulant drugs, are needed for elderly patients. Awaiting such trials, and despite some limitations, available data from existing clinical trials conducted in hospitalized medical patients supported a good benefit-risk ratio of different thromboprophylaxis modalities in geriatric patients. Nevertheless, in practice, the balance between expected benefit and risk of prophylactic anticoagulation should be carefully assessed for each individual elderly patient taking into account the specific risk of VTE in older patients and the risk of anticoagulant related bleeding probably underestimated in clinical trials. Risk assessment models developed for overall medical patients are useful tools to improve the use of thromboprophylaxis even in elderly patients, but remain to be evaluated in this specific population.

\section{Disclosures}

DM and KL were investigators for the EXCLAIM study. DM, $\mathrm{KL}$, and GLG were investigators in clinical trials evaluating new antithrombotic drugs (Sanofi Aventis, GSK, Boehringer, Léo, Bayer, BMS). None have stock holdings or options. None received salaries.

\section{References}

Agency for Healthcare Research and Quality. 2001. Making health care safer. A critical analysis of patient safety practices: summary [online]. Evidence Report/Technology Assessment Number 43. Rockville, MD: AHRQ, www.ahrq.gov/clinic/ptsafety/summary.htm.

Alikhan R, Cohen AT, Combe S,et al. 2003. Prevention of venous thromboembolism in medical patients with enoxaparin: a subgroup analysis of the MEDENOX study. Blood Coagul Fibrinolysis, 14:341-6.

Alikhan R, Cohen AT, Combe S, et al. 2004. Risk factors for venous thromboembolism in hospitalized patients with acute medical illness: analysis of the MEDENOX Study. Arch Intern Med, 164:963-8.
Anderson FA Jr, Decousus H, Bergmann JF, et al. 2003. A multinational observational cohort study in hospitalized medical patients of practices in prevention of venous thromboembolism and clinical outcomes: findings of the International Medical Prevention Registry of Venous Thromboembolism (IMPROVE). J Thromb Haemost, 1:1438.

Anderson FA Jr, Wheeler HB, Goldberg RJ, et al. 1991. A population-based perspective of the hospital incidence and case-fatality rates of deep vein thrombosis and pulmonary embolism. The Worcester DVT Study. Arch Intern Med, 151:933-8.

Arcelus JI, Caprini JA, Monreal M et al. 2003. The management and outcome of acute venous thromboembolism: a prospective registry including 4011 patients. J Vasc Surg, 38: 916-22.

Baglin TP, White K, Charles A. 1997. Fatal pulmonary embolism in hospitalised medical patients. J Clin Pathol, 50:609-10.

Belch JJ, Lowe GD, Ward AG, et al. 1981. Prevention of deep vein thrombosis in medical patients by low-dose heparin. Scott Med J, 26:115-7.

Bergmann JF, Caulin C. 1996. Heparin prophylaxis in bedridden patients. Lancet, 348:205-6.

Bergmann JF, Neuhart E. 1996. A multicenter randomized double-blind study of enoxaparin compared with unfractionated heparin in the prevention of venous thromboembolic disease in elderly in-patients bedridden for an acute medical illness. The Enoxaparin in Medicine Study Group. Thromb Haemost, 76:529-34.

Bergqvist D, Agnelli G, Cohen AT, et al. ENOXACAN II Investigators. 2002. Duration of prophylaxis against venous thromboembolism with enoxaparin after surgery for cancer. $N$ Engl J Med, 346:975-80.

Beyth RJ, Quinn LM, Landefeld CS. 1998. Prospective evaluation of an index for predicting the risk of major bleeding in outpatients treated with warfarin. Am J Med, 105:91-9.

Cade JF, Andrews JT, Stubbs AE.1982. Comparison of sodium and calcium heparin in prevention of venous thromboembolism. Aust NZ J Med, 12:501-4.

Campbell NR, Hull RD, Brant R, et al. 1996. Aging and heparin-related bleeding. Arch Intern Med, 156:857-60.

Chopard P, Dorffler-Melly J, Hess U, et al. 2005. Venous thromboembolism prophylaxis in acutely ill medical patients: definite need for improvement. $J$ Intern Med, 257:352-7.

Cohen AT, Alikhan R, Arcelus JI, et al. 2005. Assessment of venous thromboembolism risk and the benefits of thromboprophylaxis in medical patients. Thromb Haemost, 94:750-9.

Cohen AT, Davidson BL, Gallus AS, et al. ARTEMIS Investigators. 2006. Efficacy and safety of fondaparinux for the prevention of venous thromboembolism in older acute medical patients: randomised placebo controlled trial. BMJ, 332:325-9.

Collins R, Scrimgeour A, Yusuf S, et al. 1988. Reduction in fatal pulmonary embolism and venous thrombosis by perioperative administration of subcutaneous heparin. Overview of results of randomized trials in general, orthopedic, and urologic surgery. N Engl J Med, 318:1162-73.

Dahan R, Houlbert D, Caulin C, et al. 1986. Prevention of deep vein thrombosis in elderly medical in-patients by a low molecular weight heparin: a randomized double-blind trial. Haemostasis, 16:159-64.

Dentali F, Douketis JD, Gianni M, et al. 2007. Meta-analysis: anticoagulant prophylaxis to prevent symptomatic venous thromboembolism in hospitalized medical patients. Ann Intern Med, 146:278-88.

Fraisse F, Holzapfel L, Couland JM, et al. 2000. Nadroparin in the prevention of deep vein thrombosis in acute decompensated COPD. The Association of Non-University Affiliated Intensive Care Specialist Physicians of France. Am J Respir Crit Care Med, 161:1109-14.

Gardlund B. 1996. Randomised, controlled trial of low-dose heparin for prevention of fatal pulmonary embolism in patients with infectious diseases. The Heparin Prophylaxis Study Group. Lancet, 347:1357-61.

Geerts WH, Pineo GF, Heit JA, et al. 2004. Prevention of venous thromboembolism: the Seventh ACCP Conference on Antithrombotic and Thrombolytic Therapy. Chest, 126:338-400.

Goldhaber SZ, Dunn K, MacDougall RC. 2000. New onset of venous thromboembolism among hospitalized patients at Brigham and Women's Hospital is caused more often by prophylaxis failure than by withholding treatment. Chest, 118:1680-4. 
Goldhaber SZ, Savage DD, Garison RJ, et al. 1983. Risk factors for pulmonary embolism: the Farmingham Study. Am J Med, 74:1023-8.

Heit JA, O'Fallon WM, Petterson TM, et al. 2002. Relative impact of risk factors for deep vein thrombosis and pulmonary embolism. A population-based study. Arch Intern Med, 162:1245-8.

Heit JA, Silverstein MD, Mohr DN, et al. 2000. Risk factors for deep vein thrombosis and pulmonary embolism: a population-based case-control study. Arch Intern Med, 160:809-15.

Heit JA, Silvestein MD, Mohr DN, et al. 2001. The epidemiology of venous thromboembolism in the community. Thromb Haemost, 86:452-63.

Hull RD, Pineo GF, Stein PD, et al. 2001. Extended out-of-hospital lowmolecular-weight heparin prophylaxis against deep venous thrombosis in patients after elective hip arthroplasty: a systematic review. Ann Intern Med, 135:858-69.

Hull RD, Schellong SM, Tapson VF, et al. 2007. Extended-duration venous thromboembolism prophylaxis in acutely ill medical patients with recent reduced mobility: the EXCLAIM study. $J$ Thromb Haemost, 5:O-S-001.

Ibarra-Pérez C, Lau-Cortés E, Colmenero-Zubiate S, et al. 1988. Prevalence and prevention of deep venous thrombosis of the lower extremities in high-risk pulmonary patients. Angiology, 39:505-13.

Kahn SR, Panju A, Geerts W, et al. CURVE Study Investigators. 2007. Multicenter evaluation of the use of venous thromboembolism prophylaxis in acutely ill medical patients in Canada. Thromb Res, 119:145-55.

Kakkar AK, Levine MN, Kadziola Z, et al. 2004. Low molecular weight heparin, therapy with dalteparin, and survival in advanced cancer: the Fragmin Advanced Malignancy Outcome Study (FAMOUS). J Clin Oncol, 22:1944-8.

Kamphuisen PW, Agnelli G. 2007. What is the optimal pharmacological prophylaxis for the prevention of deep-vein thrombosis and pulmonary embolism in patients with acute ischemic stroke? Thromb Res, 119:265-74.

King CS, Holley AB, Jackson JL, et al. 2007. Twice vs three times daily heparin dosing for thromboembolism prophylaxis in the general medical population: A meta-analysis. Chest, 131:507-16.

Kleber FX, Witt C, Flosbach CW, et al. PRINCE Study Group. 1998. Study to compare the efficacy and safety of the LMWH Enoxaparin and standard heparin in the prevention of thromboembolic events in medical patients with cardiopulmonary diseases. Ann Hematol, 76:261.

Kniffin WD Jr, Baron JA, Barrett J, et al. 1994. The epidemiology of diagnosed pulmonary embolism and deep venous thrombosis in the elderly. Arch Intern Med, 154:861-6.

Kucher N, Koo S, Quiroz R, et al. 2005a. Electronic alerts to prevent venous thromboembolism among hospitalized patients. $N$ Engl J Med, 352:969-77.

Kucher N, Leizorovicz A, Vaitkus PT, et al. 2005b. Efficacy and safety of fixed low-dose dalteparin in preventing venous thromboembolism among obese or elderly hospitalized patients: a subgroup analysis of the PREVENT trial. Arch Intern Med, 165:341-5.

Lamy A, Wang X, Kent R, et al. 2002. Economic evaluation of the MEDENOX trial: a Canadian perspective. Can Respir J, 9:169-77.

Landefeld CS, Beyth RJ. 1993. Anticoagulant related bleeding: clinical epidemiology, prediction and prevention. Am J Med, 95:315-28.

Le Gal G, Righini M, Roy PM, et al. 2005. Differential value of risk factors and clinical signs for diagnosing pulmonary embolism according to age. $J$ Thromb Haemost, 3:2457-64.

Lechler E, Schramm W, Flosbach CW; The PRIME Study Group. 1996. The venous thrombotic risk in nonsurgical patients: epidemiologal data and efficacy/safety profile of a low molecular weight heparin (enoxaparin). Haemostasis, 26:49-56.

Lederle FA, Sacks JM, Fiore L, et al. 2006. The prophylaxis of medical patients for thromboembolism pilot study. Am J Med, 119:54-9.

Leizorovicz A, Cohen AT, Turpie AG, et al. PREVENT Medical Thromboprophylaxis Study Group. 2004. Randomized, placebo-controlled trial of dalteparin for the prevention of venous thromboembolism in acutely ill medical patients. Circulation, 110:874-9.
Levine M, Hirsh J, Gent M, et al. 1994. Double-blind randomised trial of a very-low-dose warfarin for prevention of thromboembolism in stage IV breast cancer. Lancet, 343:886-9.

Levine MN, Raskob G, Landefeld S, et al. 2001. Hemorrhagic complications of anticoagulant treatment. Chest, 119:108-21.

Lindblad B, Sternby NH, Bergqvist D. 1991. Incidence of venous thromboembolism verified by necropsy over 30 years. $\mathrm{Br}$ Med J, 302:709-11.

Lopez-Jimenez L, Montero M, Gonzalez-Fajardo JA, et al. RIETE Investigators. 2006. Venous thromboembolism in very elderly patients: findings from a prospective registry (RIETE). Haematologica, 91:1046-51.

Mahe I, Bergmann JF, d'Azemar P, et al. 2005. Lack of effect of a lowmolecular-weight heparin (nadroparin) on mortality in bedridden medical in-patients: a prospective randomised double-blind study. Eur $J$ Clin Pharmacol, 61:347-51.

McGarry LJ, Thompson D, Weinstein MC, et al. 2004. Cost effectiveness of thromboprophylaxis with a low-molecular-weight heparin versus unfractionated heparin in acutely ill medical inpatients. Am J Manag Care, 10:632-42.

Mismetti P, Laporte-Simitsidis S, Tardy B, et al. 2000. Prevention of venous thromboembolism in internal medicine with unfractionated or low-molecular-weight heparins: a meta-analysis of randomised clinical trials. Thromb Haemost, 83:14-9.

Monreal M, Kakkar AK, Caprini JA, et al. The RIETE Investigators. 2004. The outcome after treatment of venous thromboembolism is different in surgical and acutely ill medical patients. Findings from the RIETE registry. J Thromb Haemost, 2:1892-8.

Nicolaides AN, Breddin HK, Fareed J, et al. 2001. Prevention of venous thromboembolism. International Consensus Statement. Guidelines compiled in accordance with the scientific evidence. Int Angiol, 20:1-37.

Nuijten MJ, Berto P, Kosa J, et al. 2002. Cost-effectiveness of enoxaparin as thromboprophylaxis in acutelly ill medical patients from the Italian NHS perspective. Recenti Prog Med, 93:80-91.

Oger E. EPI-GETBO Study Group. 2000. Incidence of venous thromboembolism: a community-based study in Western France. Thromb Haemost, 83:657-60.

Oger E, Bressolette L, Nonent M, et al. 2002. High prevalence of asymptomatic deep vein thrombosis on admission in a medical unit among elderly patients. The TADEUS Project. Thromb Haemost, 88:592-7.

Pitt A, Anderson ST, Habersberger PG, et al. 1980. Low dose heparin in the prevention of deep-vein thromboses in patients with acute myocardial infarction. Am Heart J, 99:574-8.

Righini M, Goehring C, Bounameaux H, et al. 2000. Effects of age on the performance of common diagnostic tests for pulmonary embolism. Am J Med, 109:357-61.

Righini M, Le Gal G, Perrier A, et al. 2005. The challenge of diagnosing pulmonary embolism in elderly patients: influence of age on commonly used diagnostic tests and strategies. J Am Geriatr Soc, 53:1039-45.

Rosendaal FR. 1999. Venous thrombosis: a multicausal disease. Lancet, 353:1167-73.

Samama MM, Cohen AT, Darmon JY, et al. 1999. A comparison of enoxaparin with placebo for the prevention of venous thromboembolism in acutely ill medical patients. Prophylaxis in Medical Patients with Enoxaparin Study Group. N Engl J Med, 341:793-800.

Samama MM, Dahl OE, Mismetti P, et al. 2006. An electronic tool for venous thromboembolism prevention in medical and surgical patients. Haematologica, 91:64-70.

Samama MM, Dahl OE, Quinlan DJ, et al. 2003. Quantification of risk factors for venous thromboembolism: a preliminary study for the development of a risk assessment tool. Haematologica, $88: 1410-21$.

Samama MM. 2000. An epidemiologic study of risk factors for deep vein thrombosis in medical outpatients: the SIRIUS study. Arch Intern Med, 160:3415-20.

Sandler DA, Martin JF.1989. Autopsy proven pulmonary embolism in hospital patients: are we detecting enough deep vein thrombosis? $J R$ Soc Med, 82:203-5. 
Schadlich PK, Kentsch M, Weber M, et al. 2006. Cost effectiveness of enoxaparin as prophylaxis against venous thromboembolic complications in acutely ill medical inpatients: modelling study from the hospital perspective in Germany. Pharmacoeconomics, 24:571-91.

Sherman DG, Albers GW, Bladin C, et al. PREVAIL Investigators. 2007. The efficacy and safety of enoxaparin versus unfractionated heparin for the prevention of venous thromboembolism after acute ischaemic stroke (PREVAIL Study): an open-label randomised comparison. Lancet, 369:1347-55.

Shorr AF, Jackson WL, Weiss BM, et al. 2007. Low-molecular weight heparin for deep vein thrombosis prophylaxis in hospitalized medical patients: results from a cost-effectiveness analysis. Blood Coagul Fibrinolysis, 18:309-16.

Tapson VF, Decousus H, Pini M, et al. IMPROVE Investigators. 2007. Venous thromboembolism prophylaxis in acutely ill hospitalized medical patients: findings from the International Medical Prevention Registry on Venous Thromboembolism. Chest, 132:936-45.
Warkentin TE, Greinacher A. 2004. Heparin-induced thrombocytopenia: recognition, treatment, and prevention. The Seventh ACCP Conference on Antithrombotic and Thrombolytic Therapy. Chest, 126:311-37.

Warkentin TE, Levine MN, Hirsh J, et al. 1995. Heparin-induced thrombocytopenia in patients treated with low-molecular-weight heparin or unfractionated heparin. $N$ Engl J Med, 332:1330-5.

Wein L, Wein S, Haas SJ, et al. 2007. Pharmacological venous thromboembolism prophylaxis in hospitalized medical patients. A meta-analysis of randomized controlled trials. Arch Intern Med, 167:1476-86.

White RH, Beyth RJ, Zhou H, et al. 1999. Major bleeding after hospitalization for deep-venous thrombosis. Am J Med, 107:414-24. 
